Copyright by EDP Sciences. Chen, Y.; Jiao, Y.; Sun, C. L.; Chen, X. J., "Calibrating virtual population analysis for fisheries stock assessment," Aquat. Living Resour. 21, 89-97 (2008). DOI: http://dx.doi.org/10.1051/alr:2008030

\title{
Calibrating virtual population analysis for fisheries stock assessment
}

\author{
Yong Chen ${ }^{1,4, a}$, Yan Jiao ${ }^{2}$, Chi-Lu Sun ${ }^{3}$ and Xinjun $\mathrm{Chen}^{4}$ \\ 1 School of Marine Sciences, University of Maine, Orono, Maine 04469, USA \\ 2 Department of Fisheries and Wildlife Sciences, Virginia Tech Blacksburg, VA 24061, USA \\ 3 Institute of Oceanography, National Taiwan University, 1 Section 4 Roosevelt Road, Taipei, Taiwan 10617, China \\ 4 The Key Laboratory of Shanghai Education Commission for Oceanic Fisheries Resources Exploitation, Shanghai Fisheries University, \\ Shanghai 200090, China
}

Received 29 December 2007; Accepted 7 April 2008

\begin{abstract}
Virtual population analysis (VPA) is often used for assessing freshwater and marine fisheries resources. One important component in VPA is to calibrate abundance estimates with a time series of abundance indices. One of the commonly used calibration processes usually includes simultaneous estimation of cohort sizes across all ages and years. This reduces the flexibility of the model in accounting for age- and year-effects, in particular in the presence of an age-specific curvilinear relationship between abundance index and stock abundance. In this study, we compared this simultaneous method tuning approach with a stepwise approach which calibrates abundance age by age in tuning VPA. The simulation study suggests that the stepwise procedure tends to perform better with no obvious retrospective errors in the estimated stock biomass compared with the simultaneous method which tends to have large positive retrospective errors. In applying the stepwise procedure and simultaneous method to a cod fishery data set, we found large differences in the stock sizes estimated for the most recent year using these two methods, with the current stock size estimated using the stepwise method being substantially smaller than that estimated with the simultaneous method. Considering the likelihood of the presence of curvilinear relationship between abundance index and stock abundance, we conclude that the stepwise method yields more reliable results, and is less risk-prone in using VPA for fisheries stock assessment.
\end{abstract}

Key words: Virtual population analysis (VPA) / Calibration / Stepwise procedure / Retrospective problem / Stock assessment, and simulation

Résumé - Calibrer l'analyse de population virtuelle pour évaluer les stocks de pêche. L'analyse de population virtuelle (VPA) est souvent utilisée pour estimer les ressources halieutiques des eaux continentales ou marines. Une phase importante en VPA est la calibration des estimations de l'abondance des cohortes en utilisant une ou des séries temporelles d'indices d'abondance. Une des méthodes couramment utilisée consiste à estimer simultanément l'abondance des cohortes sur l'ensemble des âges et des années. On diminue la flexibilité du modèle en prenant en compte ainsi des effets âge - année, en particulier lorsqu'il existe des relations non linéaires propres à chaque âge entre les indices d'abondance et l'abondance dans le stock. Dans cette étude, nous comparons cette méthode globale de calibration à une approche pas à pas qui consiste à calibrer l'abondance des cohortes âge après âge. L'étude de simulation montre que la procédure pas à pas tend à mieux opérer, sans erreur rétrospective évidente dans l'estimation de la biomasse du stock, comparée à la méthode globale qui génère rétrospectivement de fortes erreurs positives. En appliquant ces deux méthodes à un jeu de données issues d'une pêcherie de morue, nous avons mis en évidence de grandes différences dans les estimations du stock pour les années les plus récentes, la taille du stock finalement estimée en utilisant la méthode pas à pas, étant beaucoup plus petite que celle par la méthode globale. En considérant la probabilité de l'existence d'une relation non linéaire entre les indices d'abondance et l'abondance dans le stock, nous concluons que la méthode, pas à pas, donne des résultats plus fiables, et est d'un usage moins risqué quand la VPA est utilisée pour évaluer les stocks exploités par la pêche.

a Corresponding author: ychen@maine.edu 


\section{Introduction}

Although many sophisticated stock assessment methods have been developed (Quinn and Deriso 1999), a relatively simple method, virtual population analysis (VPA), is still commonly used for assessing freshwater and marine fisheries resources because of its moderate data requirement and simple algorithm (Megrey 1989; de Valpine 2002; Chatfield 2003; Xiao 2007). The VPA often incorporates auxiliary information such as abundance indices obtained from surveys and fisheries to tune its estimation (Hilborn and Walters 1992). Many methods have been developed to tune VPA (Xiao 2007), ranging from some ad hoc methods (e.g., Smith and Gavaris 1993; Darby and Flatman 1994; Patterson and Kirkwood 1995) to extended survivors analysis (Shepherd 1999). A tuned method commonly used with VPA in the eastern USA and Atlantic Canada is based on a nonlinear regression model (Gavaris 1988, 1993; Smith and Gavaris 1993), in which parameters are estimated by the least squares method that minimizes the sum of squared differences between the log observed and the predicted abundance indices simultaneously for each age class in complete cohorts and incomplete cohorts. A complete cohort is defined as the cohort that has passed thorough the fishery (i.e. individuals in the cohort no longer contribute to the fishery catch), and an incomplete cohort is defined as the cohort that is still contributing to the fishery at the time of stock assessment.

The objective function for this commonly used VPA model can thus be written as

$$
\text { Minimize } \sum_{a=1}^{A} \sum_{y=1}^{Y}\left[\ln \left(I_{a, y}\right)-\ln \left(q_{a} N_{a, y}\right)\right]^{2},
$$

where $I_{a, y}$ is the observed abundance index for fish of age $a$ at the beginning of year $\mathrm{y}, N_{a, y}$ is the number of fish of age $a$ still alive at the beginning of year $y, A$ is the terminal age, $Y$ is the most recent year when catch and abundance index data are available (most likely a year before stock assessment is conducted), and $q_{a}$ is the catchability coefficient of fish in age $a$. This equation is derived from the statistical model,

$$
I_{a, y}=q_{a} N_{a, y} e^{\varepsilon_{a, y}}, \quad \varepsilon_{a, y} \in N\left(0, \sigma^{2}\right) .
$$

For a cohort in a fishery, $N_{a, y}$ is approximately calculated as

$$
N_{a, y}=N_{a+1, y+1} e^{M}+C_{a, y} e^{\frac{M}{2}},
$$

where $M$ is the instantaneous rate of natural mortality and $C_{a, y}$ is catch of fish at age $a$ in year $y$. For a complete cohort, cohort size at the terminal age is often estimated iteratively by assuming fishing mortality at the terminal age to be as a function or average of mortality rates for ages close to the terminal age (Hilborn and Walters 1992), and thus sizes of other age classes for this cohort can be back-calculated with equation (3), using only catch-at-age data. For incomplete cohorts, however, the cohort sizes in the current year are unknown parameters that must be estimated (Xiao 2007).

A nonlinear parameter estimation method is often used to simultaneously estimate cohort sizes across all ages and years (Quinn and Deriso 1999). Such an estimation process may reduce the flexability of the model in accounting for age- and year-effects, particularly in the presence of a curvilinear relationship between abundance index and stock abundance resulting from size-/age-dependent distributions (Secor 2007). In the parameter estimation, cohort sizes are estimated as unknown parameters when cohorts are incomplete cohorts, but become observations of the independent variables in the VPA model when the cohorts become complete in the fishery.

The tuned VPA, defined by equation (1) and thereafter referred to as "simultaneous method", tends to have the retrospective problem defined as the consistent overestimation of current stock size compared with subsequent estimates for the same year as additional years of data are added to the same model (Sinclair et al. 1990; ICES 1991; Mohn 1993; Rajakaruna et al. 2005). A Bayesian analysis by Walters and Maguire (1996) suggests that setting the exponential value of power function between 0 and 1 in the observation model results in lower estimated values of the current size of incomplete cohorts, indicating retrospective problem may be related to mis-specification of functional relationship between stock abundance and abundance index.

In this study, we used a simple algorithm which estimates the current size of each incomplete cohort in a stepwise fashion (as opposed to simultaneous estimation across all ages and years) based on the relationship between estimated sizes of completed cohorts and abundance indices. We compared the stepwise algorithm with the simultaneous method defined by equation (1), using a simulated fishery in the presence of curvilinear relationship between abundance index and stock abundance. We used the curvilinear function in simulating the relationship between abundance index and stock abundance because it tends to be more realistic in fisheries (Hilborn and Walters 1992). We also applied both the approaches to the Atlantic cod data in NAFO subdivision $2 \mathrm{~J} 3 \mathrm{KL}$. We then compared the results derived from the stepwise algorithm and simultaneous method in estimating current stock biomass and discussed the management implications of potential errors in stock biomass estimates.

\section{The stepwise algorithm}

Let $a=$ age, $a=1, \ldots, A$; and $y=$ year, $y=1, \ldots, Y$. For a complete cohort that has passed through the fishery, we can estimate the number of fish at terminal age iteratively by assuming fishing mortality at the terminal age being a function of fishing mortality rates for ages close to the terminal age and back-calculate $N_{A}, N_{A-1}, \ldots$, and $N_{1}$ for each complete cohort (Hilborn and Walters 1992). For an $A x \times Y$ catch-at-age matrix, the total number of cohorts is $A+Y-1$ (Paloheimo 1980). Among these cohorts, $Y-1$ cohorts are completed in the fishery. Their sizes at age can be estimated from the above equation and catch (Hilborn and Walters 1992). For the other Aincomplete cohorts, we need to estimate their current sizes (i.e., $N_{a, Y}$, where $a=1, \ldots, A$ ) using additional information or making some extra assumptions. In this study, we consider the situation where we have an abundance index of $A \times Y$ matrix.

Unlike the simultaneous approach, the stepwise algorithm estimates $N_{1, Y}, \ldots, N_{A, Y}$ age by age starting from $N_{A, Y}$. For fish at age group $A$, we have their size estimates for years of 1 to 
$Y-1$ from the completed cohorts. Using abundance indices observed for these fish in the same period of time, we can fit a log-linear model to these $Y-1$ observations. For age group $A$, the model can be written as

$$
\begin{aligned}
\ln \left(I_{A, j}\right) & =b_{A, 0}+b_{A, 1} \ln \left(N_{A, j}\right)+\varepsilon_{A, j}, \quad \varepsilon_{A, j} \in N\left(0, \sigma_{A}^{2}\right), \\
j & =1, \ldots, Y-1 .
\end{aligned}
$$

Parameters $b_{A, 0}$ and $b_{A, 1}$ can be estimated by minimizing the sum of squared differences between the observed $\ln \left(I_{A, j}\right)$ and $\ln \left(\hat{I}_{A, j j}\right)$ predicted from the above equation. After these two parameters are estimated, the current size for fish at age $A$ in year $Y, N_{A, Y}$, can be estimated as

$$
\hat{N}_{A, Y}=\exp \left[\frac{\ln \left(I_{A, Y}\right)-b_{A, 0}}{b_{A, 1}}\right] .
$$

This is the estimate of current size for the $Y^{\text {th }}$ cohort of fish in the fishery.

Based on this estimate, we can back-calculate the sizes of this cohort in year $Y-1, Y-2, \ldots$, and 1 . Thus, for fish of age $A-2$, we have their size estimates for years from 1 to $Y-1$. The size estimates for years 1 to $Y-2$ are estimated from the completed cohorts, while the size estimate for year $Y-1$ is from the $Y^{\text {th }}$ cohort calculated above. We can then estimate the current size at age $A-2$ (i.e., $N_{A-1, Y}$ ) from the linear regression analysis. Repeat the same procedure, we can estimate sizes for all incomplete cohorts. Thus, at the youngest age, there would be $Y-A$ estimates of abundance from complete cohorts, $A-2$ estimates of abundance based on sequential prediction of abundance. These data points were used to regress against the relevant abundance indices to derive a regression equation for the youngest age. The derived regression equation was then used to estimate size for the youngest age in the current year (i.e., $Y$ ) from its relevant abundance index.

\section{Simulation study}

We conducted a simulation study to compare the stepwise procedure with the simultaneous method. The following simulation algorithm was used: (1) identify $N$ matrix (number of fish in age $a$ still alive at the beginning of year $y$ ), using the $N$ matrix estimated in the northern cod in stock assessment report (Shelton et al. 1996); (2) identify fishing mortality $\boldsymbol{F}$ matrix for fish of different ages and year, again using data for the northern cod; (3) calculate the "true" catch-atage matrix from the $\boldsymbol{N}$ matrix and $\boldsymbol{F}$ matrix; (4) calculate the "true" age composition of catch for each year from the "true" catch-at-age matrix; (5) calculate the "true" total catch for each year from catch-at-age matrix as "True" $C_{y}=\sum_{a=1}^{A} C_{a, y}$; (6) conduct multinominal sampling with a subsample size $n$ and "true" age composition in step (4) to derive "observed" age composition of catch for each year; (7) assume a log-normal error for the "observed" total catch in year $y, C_{y}=$ "True" $C_{y} e^{\varepsilon_{y}}$, where $\varepsilon_{y}$ follows a normal distribution with mean of 0 and standard deviation of 0.2 ; (8) multiply "observed" catch (i.e., step 7) with "observed" age composition of catch (i.e.,

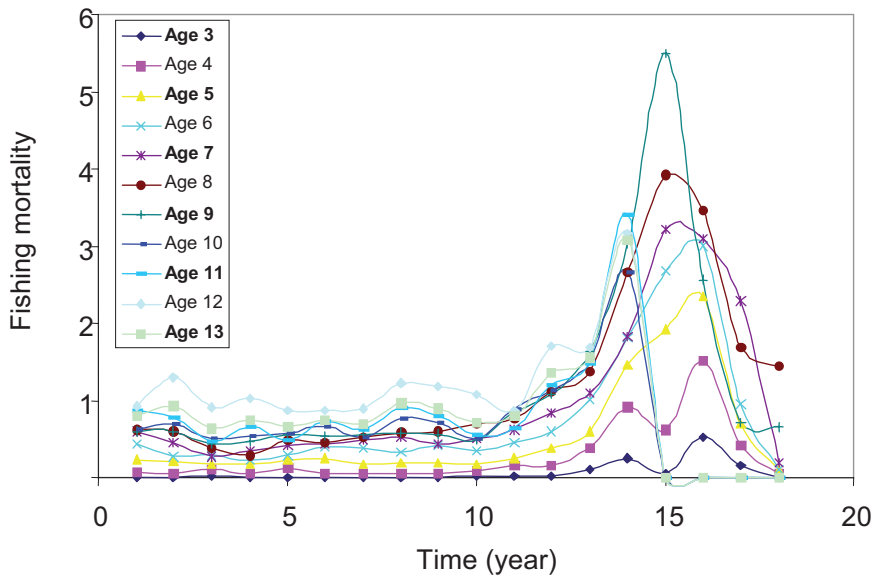

Fig. 1. True fishing mortality for fish of different ages in different years used in the simulation (e.g. Age 3 close to the $X$-axis).

step 6) to derive "observed" catch-at-age matrix; (9) calculate "true" abundance index $I_{a, y}=q_{a} N_{a, j}^{\gamma_{a}}$, where $N_{a, j}$ is the "true" stock abundance of fish in age $a$ in year $y$, and $\gamma_{a}$ is an age-specific density-dependent factor describing possible nonlinear relationship between the abundance index and stock abundance; (10) calculate the "observed" abundance index as Observed $I_{a, y}=I_{a, y} e^{\varepsilon_{a, y}}$, where $\varepsilon_{a, y}$ follows a normal distribution with mean of 0 and standard deviation of 0.2 ; (11) apply the simultaneous method and stepwise procedure to the "observed" catch-at-age matrix and 'observed" abundance index to estimate stock abundance $N_{a, y}$ and stock biomass $B_{y}$, where $B_{y}$ is stock biomass in year $y$ and can be calculated from the estimated $N_{a, y}$ and a weight-at-age matrix; and (12) calculate the ratio of estimated and "true" stock biomasses (from true $N$ matrix and weight-at-age-matrix) for both simultaneous method and stepwise procedure. The "true" fishing mortality for different age groups in different years used in the simulation is described (Fig. 1).

The subsample size $n$ in step (6) determines the variation associated with age composition data. Two subsample sizes were considered for $n, 1000$ and 2000. The "observed" age composition data derived from $n$ of 1000 in step (6) have larger variations than those from $n$ of 2000. The values of $\gamma$ in step (9) have been found to vary with age for the Atlantic cod. To reflect such a variation, we used the following values for $\gamma$ estimated from the northern cod data in the simulation: $0.51,0.65$, $0.89,0.98,0.99,1.52,1.54,1.34,1.40,1.36$, and 1.71 for fish of ages 3 to 13 .

Steps (6) to (12) described above were repeated for 100 times to yield 100 sets of ratio of estimated stock biomass versus "true" stock biomass for the simultaneous method and stepwise procedure. Box plot was used to summarize the ratios derived in the 100 simulation runs. The mean values of the ratio in the 100 simulation runs smaller than, equal to and larger than 1 imply negative estimation bias, no estimation bias, and positive estimation bias, respectively. The rooted mean square errors (RMSE) for stock biomass estimated in 
year $y, \operatorname{RMSE}\left(\hat{B}_{y}\right)$, was calculated as

$$
\operatorname{RMSE}\left(\hat{B}_{y}\right)=\sqrt{\frac{\sum_{k=1}^{100}\left(B_{y, k} \wedge-B_{y, k}\right)^{2}}{100}},
$$

where $k$ indicates the $k^{\text {th }}$ simulation run. The percentage estimation error for estimated biomass in year $y, \operatorname{PEE}\left(\hat{B}_{y}\right)$, was calculated as

$$
\operatorname{PEE}\left(\hat{B}_{y}\right)=\frac{R M S E\left(\hat{B}_{y}\right)}{B_{y}} \times 100 \%
$$

The PEE calculated in equation (7) measures the overall estimation errors including both estimation biases and variations in estimates among the 100 simulation runs. For recent years, an estimation procedure with small estimation bias and PEE suggests that it performs well and tends to have smaller retrospective errors in estimating current stock biomass.

\section{Application to the actual data}

The stepwise procedure was applied to catch-at-age data obtained from the cod fishery in the NAFO subdivision 2J3KL. The catch-at-age data available in this fishery are from 1962 to 1995 for fish of ages 3 to 20 years old. The survey data are available from 1978 to 1995 for cod of age 3 to 12 . Thus, only data from 1978 to 1995 for fish of age 3 to 12 were used in the VPA analysis. For the complete cohorts, because age 12 was not the terminal age, we could not use the approach similar to those used when an age could be assumed to be terminal age. Instead, for each complete cohort, we used the number of fish estimated for age 13 in actual assessment report (Shelton et al. 1996) as starting values for back-calculating the number of fish for each complete cohort in different age classes. The simultaneous method had been applied to the same data set for estimating stock sizes and deriving the TAC in the assessment and management of this cod stock (Shelton et al. 1996). For the complete cohorts, the cohort sizes of fish in different age classes were the same for both the simultaneous method and stepwise procedure, and the results were compared. Because this study was only for the purpose of comparing the two methods, the interpretation of management implications for the cod fisheries should be cautious.

\section{Results}

\subsection{Simulation}

For simulation scenarios with two different subsample sizes (1000 for scenario I and 2000 for scenario II), the PEE values were almost identical between stock biomasses of the first 15 years estimated using the simultaneous method and stepwise method. The differences were small for year 16, but for the last two years (i.e., years 17 and 18) the stock biomasses estimated using the simultaneous method had much

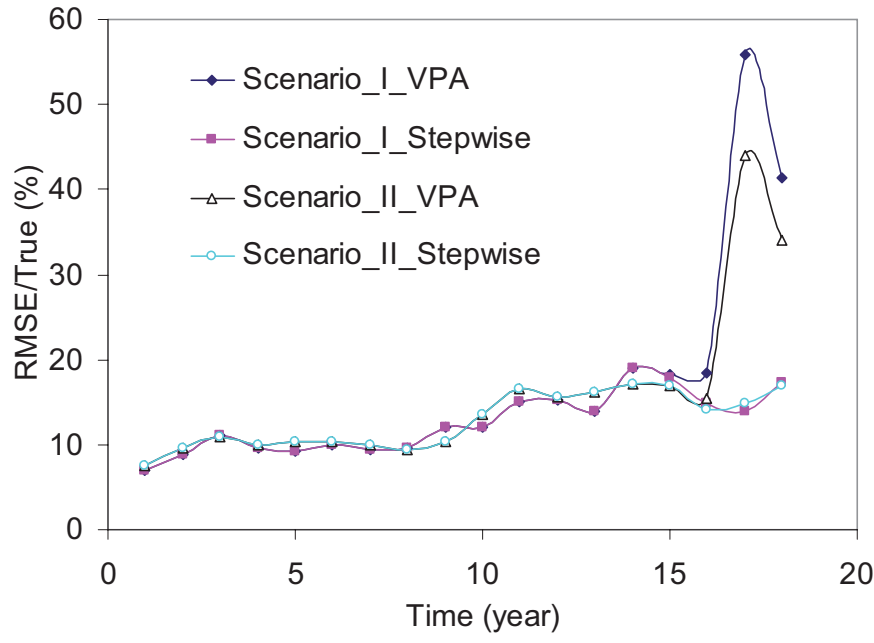

Fig. 2. Percentage estimation errors (PEEs) calculated using equation (7) in estimating stock biomass. The scenario I refers to simulated data with subsampling size of 1000 and scenario II refers simulated data with subsampling size of 2000 in simulating age composition data. VPA refers to the simultaneous method; Rooted mean square errors (RMSE).

higher PEEs compared with the PEEs associated with stock biomasses estimated using the stepwise method (Fig. 2). Thus, the simultaneous method tended to yield much larger estimation errors for stock biomass in the most recent two years compared with the stepwise procedure. The substantial increases in the PEEs for the stock biomasses estimated with the common VPA method in the most two recent years suggest the presence of large retrospective errors. The PEEs associated with the stepwise-estimated stock biomasses, however, did not increase for the last two years (Fig. 2).

For simulation scenario with a subsample size of 2000 fish, the mean of ratios between the estimated and true stock biomasses in the box plots, which summarize the stock biomasses estimated in the 100 simulation runs, tended to be close to one for the first 16 years for both methods (Figs. 3a,b), suggesting small biases in estimating stock biomasses for these 16 years using both methods. For the last two years, however, the mean of ratios between the stock biomass estimated using the common VPA and true stock biomass increased to over 1.5, suggesting that the common VPA method overestimated the true stock biomasses in the most recent two years by over $50 \%$, probably resulting from the retrospective problem. For the stepwise procedure, however, the mean value of the ratios were close to one for all the years including the two most recent years and there was no obvious increase in recent years, indicating no retrospective problem for the stepwise procedure. Similar results were observed for scenario II when errors associated with age composition data were increased (Figs. 3c,d).

\subsection{Application}

The log-transformed mean number of fish at age per tow (i.e. abundance index) was positively related with the number of fish at age in the stock estimated (Fig. 4). Their regression 

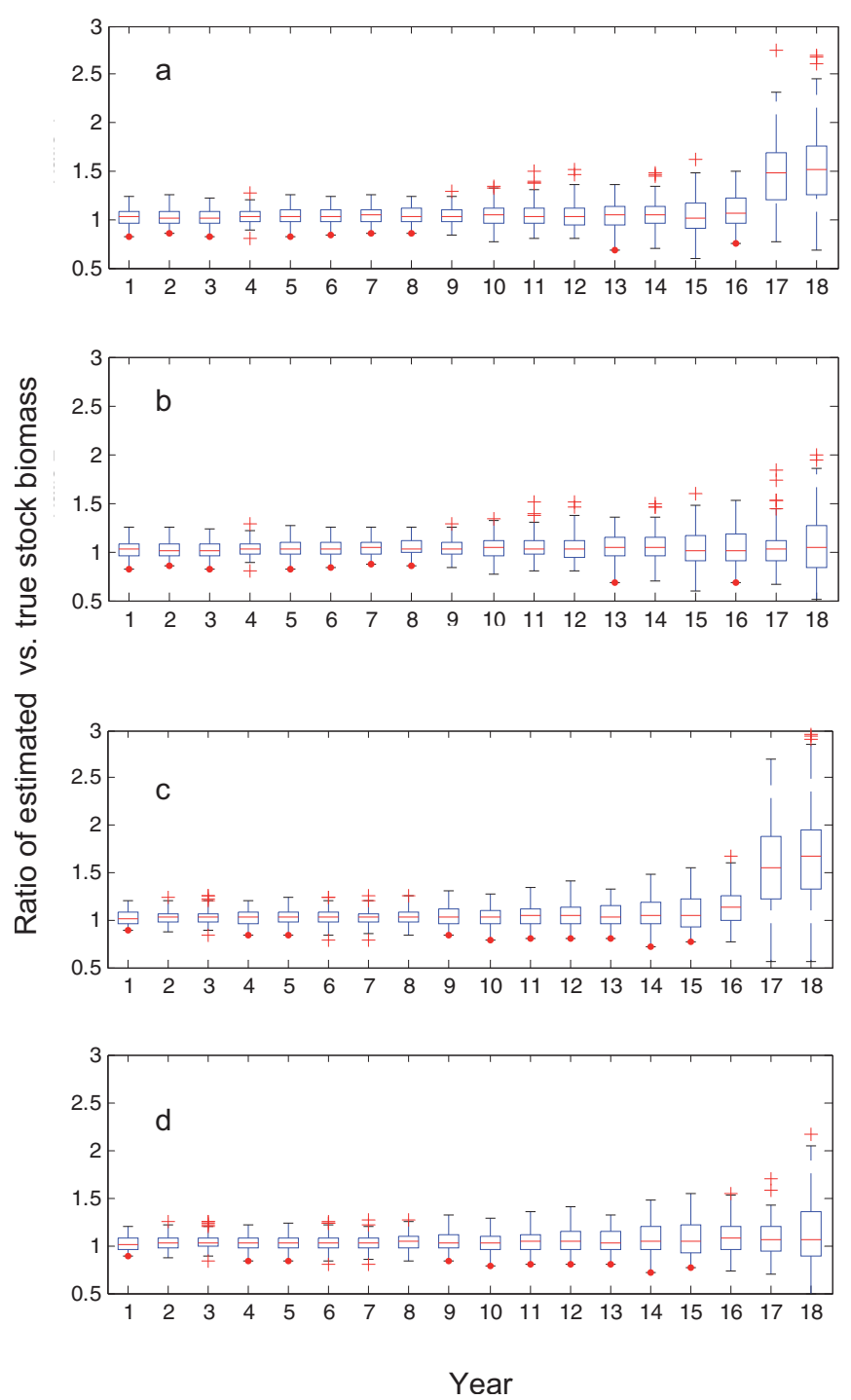

Fig. 3. Box plot of the ratios of estimated stock biomass versus true stock biomass yielded from the 100 simulation runs for different subsampling sizes in estimating age compisition data. The standard deviation of normally distributed errors for both landings and survey abundance index is $0.2 ; a$ : simultaneous method with subsample size of $1000 ; b$ : stepwise approach with subsample size of $1000 ; c$ : simultaneous method with subsample size of 2000; and $d$ : stepwise approach with subsample size of 2000 .

equations derived in the stepwise procedure were significant for fish from ages 5 to 12 years old ( $p<0.05$; Table 1 ). The significance levels of the regression equations for fish of ages 3 and 4 were 0.10 and 0.07 , respectively. Slope $b_{1}$ in the regression equation was not significantly different from 1 for each age group. For fish of age groups from 5 to 12 , intercept $b_{0}$ was significantly different from 0 . The $b_{0}$ value did not differ significantly from 0 for fish of age 3 and 4 years old. In general, the $r^{2}$ values increased with ages (Table 1). For fish of ages 7 to 11 , more than $80 \%$ of variations in abundance indices were explained by the stock size data $\left(r^{2}>0.80\right)$. The percentages of the variations in abundance indices being explained by
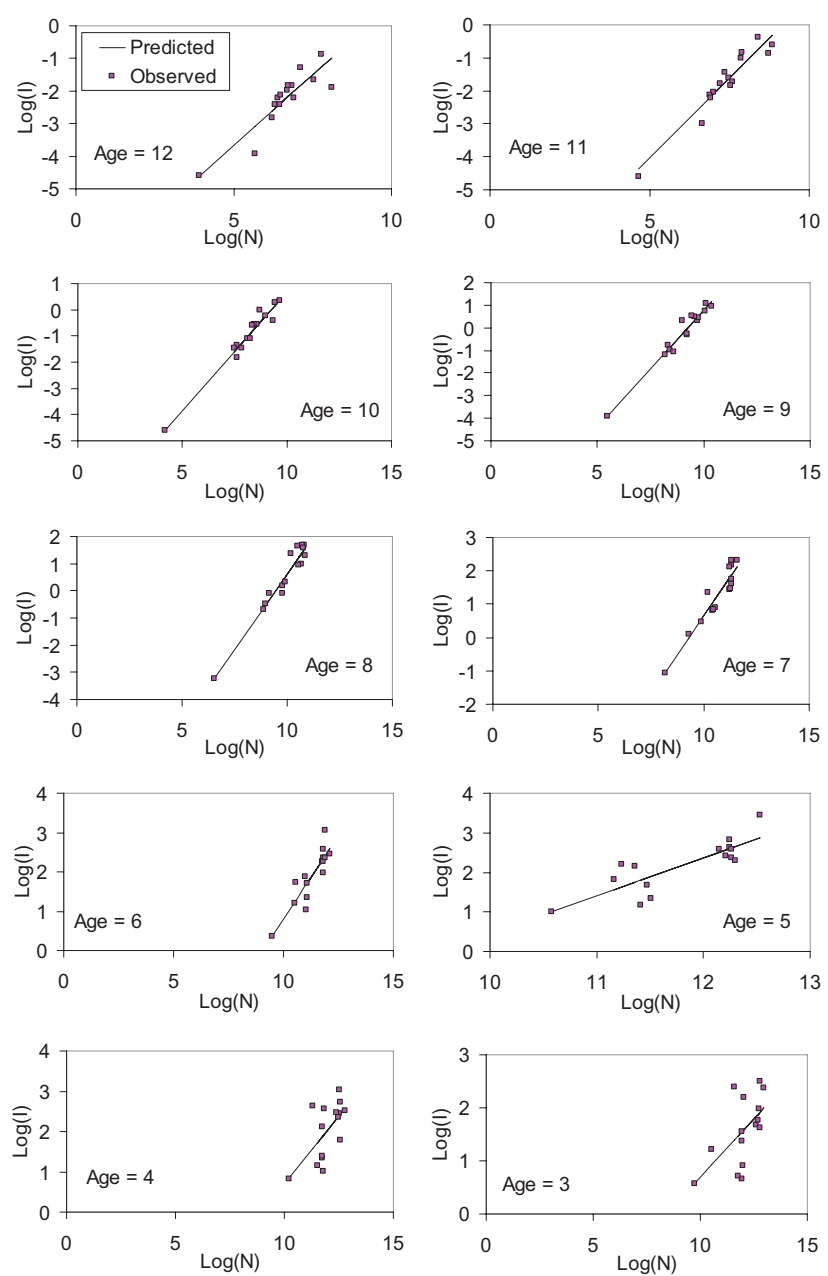

Fig. 4. Plot of logarithmic abundance index $(\log (I))$ and cohort size $(\log (N))$ for different age groups.

Table 1. Summary of regression analyses based on equation (4) between observed abundance indices and stock sizes for each age group using the stepwise procedure.

\begin{tabular}{lcccc}
\hline Age & $b_{0}$ & $b_{1}$ & $\mathrm{SE}\left(b_{1}\right)$ & $r^{2}$ \\
\hline 12 & -7.967 & 0.863 & 0.193 & 0.63 \\
11 & -8.891 & 0.970 & 0.128 & 0.83 \\
10 & -8.435 & 0.913 & 0.102 & 0.87 \\
9 & -9.533 & 1.030 & 0.105 & 0.89 \\
8 & -10.529 & 1.116 & 0.130 & 0.86 \\
7 & -8.586 & 0.924 & 0.131 & 0.81 \\
6 & -7.774 & 0.856 & 0.179 & 0.66 \\
5 & -9.116 & 0.957 & 0.225 & 0.60 \\
4 & -6.084 & 0.677 & 0.339 & 0.25 \\
3 & -3.646 & 0.435 & 0.240 & 0.22 \\
\hline
\end{tabular}

stock sizes were over $60 \%$ for fish of age 12,6 , and 5 years old, but were less than $25 \%$ for age groups 3 and 4 .

The number of fish at the beginning of 1992 estimated using the common VPA method was much higher than that estimated using the stepwise procedure for each age group. The stock size estimated with the simultaneous method was at least more than two times as large as the size estimated using 
Table 2. The abundance of cod for year 1992 estimated in year 1992 using the simultaneous method and the stepwise procedure.

\begin{tabular}{lccc}
\hline Age & Stepwise & Common VPA & Ratio $^{1}$ \\
\hline 3 & 16601 & 76979 & 4.64 \\
4 & 27468 & 78902 & 2.87 \\
5 & 39052 & 124710 & 3.19 \\
6 & 13304 & 42599 & 3.20 \\
7 & 3490 & 9451 & 2.71 \\
8 & 702 & 1823 & 2.60 \\
9 & 235 & 603 & 2.57 \\
10 & 66 & 320 & 4.85 \\
11 & 106 & 245 & 2.31 \\
12 & 49 & 121 & 2.47 \\
\hline \multirow{2}{*}{ Ratio $=\frac{\text { Cohort size estimated with simultaneous method }}{\text { Cohort size estimated with stepwise procedure }}$}
\end{tabular}

Table 3. The abundance of cod for year 1992 estimated in year 1995 using the simultaneous method and the stepwise procedure.

\begin{tabular}{lccc}
\hline Age & Stepwise & \multicolumn{2}{c}{ Common VPA Ratio ${ }^{1}$} \\
\hline 3 & 9714 & 10565 & 1.09 \\
4 & 9373 & 14591 & 1.56 \\
5 & 19084 & 24471 & 1.28 \\
6 & 14553 & 16505 & 1.13 \\
7 & 5229 & 5490 & 1.05 \\
8 & 1557 & 1607 & 1.03 \\
9 & 421 & 443 & 1.05 \\
10 & 222 & 220 & 0.99 \\
11 & 116 & 115 & 0.99 \\
12 & 21 & 20 & 0.95 \\
\hline${ }^{1}$ Ratio $=\frac{\text { Cohort size estimated with simultaneous method }}{\text { Cohort size estimated with stepwise procedure }}$
\end{tabular}

the stepwise method for each age group (Table 2). Thus, the common VPA yielded a much more optimistic estimate for the current stock size.

The size for each age group in year 1992 was estimated again in year 1995 with the four more years of extra data. The sizes of most age groups in year 1992 estimated using the common VPA in 1995 were almost identical to those estimated using the stepwise approach in 1995 (Table 3). The differences between the common VPA- and stepwise-estimated sizes were much smaller compared with those estimated in 1992 for each age group (Tables 2 and 3 ). The sizes of all age groups in year 1992 estimated in 1995 were consistently much smaller than those estimated in 1992 for the common VPA (Table 4) an indication of having retrospective problem. For the stepwise approach, however, differences between the estimates made in 1992 and 1995 were much smaller (Table 4). More importantly, the sizes estimated in 1995 were not always lower than those estimated in 1992 (Table 4), suggesting that the retrospective problem was not obvious for the stepwise approach.

The stock biomass estimated in 1992 using the common VPA approach had the temporal trend similar to that for the stepwise approach (Fig. 5). However, differences increased in more recent years, with the stepwise-estimated stock biomass being much lower. The stock biomass of 1992 estimated in 1992 using the common VPA method (i.e. 243459 t) was
Table 4. Comparisons of stock size for 1992 estimated in 1992 and in 1995 for the simultaneous method and the stepwise procedure.

\begin{tabular}{lcc}
\hline Age & Ratio $^{1}$ & Ratio $^{2}$ \\
\hline 3 & 7.29 & 1.71 \\
4 & 5.41 & 2.93 \\
5 & 5.10 & 2.05 \\
6 & 2.58 & 0.91 \\
7 & 1.72 & 0.67 \\
8 & 1.13 & 0.45 \\
9 & 1.36 & 0.56 \\
10 & 1.45 & 0.30 \\
11 & 2.13 & 0.91 \\
12 & 6.05 & 2.33 \\
\hline
\end{tabular}

${ }^{1}$ Ratio $1=\frac{\text { Cohort size estimated in } 1992 \text { with simultaneous method }}{\text { Cohort size estimated in } 1995 \text { with simultaneous method }}$

${ }^{2}$ Ratio2 $=\frac{\text { Cohort stock size estimated in } 1992 \text { with stepwise }}{\text { Cohort stock size estimated in } 1995 \text { with stepwise }}$

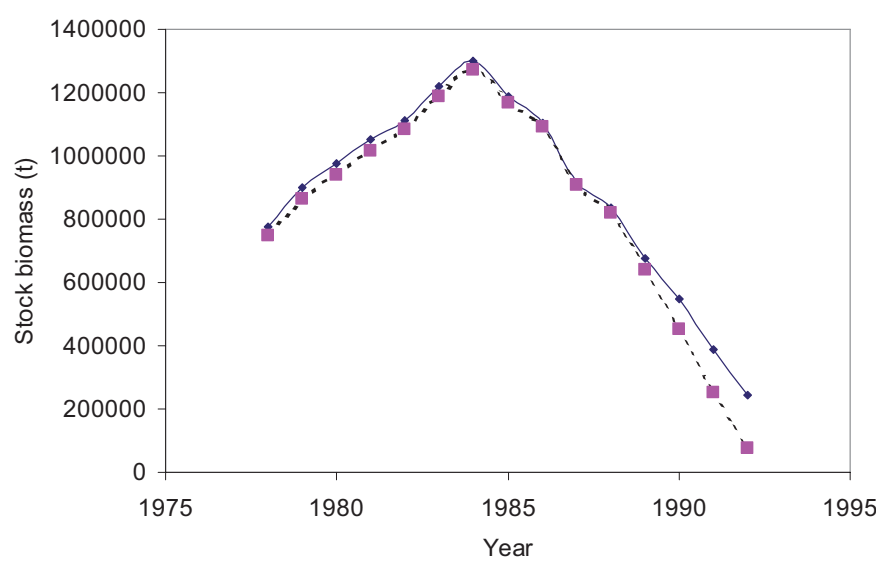

Fig. 5. Stock biomass estimated for the northern cod from 1978 to 1992. Squares are those estimated using the stepwise procedure and dots are those estimated using the simultaneous method.

much higher than that estimated using the stepwise approach (i.e. 76986 t; Fig. 5).

\section{Discussion}

The retrospective error (RE) is a disagreement of contemporaneous estimates of stock parameters with their subsequent estimates for the same year as additional years of data are added to the same model (Mohn 1993). RE as a point estimate displays mostly a trend rather than a random pattern in subsequent years (Mohn 1993). Obtaining a systematic trend in RE in a time series of estimations of stock parameters is known as the retrospective problem (Mohn 1999). In most stocks, REs in the current stock size estimates were positive in the successive assessments (Rivard and Foy 1987; Gascon 1988; Sinclair et al. 1990; ICES 1991; NRC 1998). Hence, retrospective problem is commonly referred to as obtaining a time series of positive RE in estimating current stock sizes.

Understanding the retrospective problem is vital in stock assessments. When the retrospective problem exists, catch levels are likely to be recommended higher than optimal (e.g., maximum sustainable) levels, leading to the overexploitation 
of the stocks over a number of successive years. This temporal pattern of overexploitation does not provide the stock with a recovery time, and may eventually collapse the stock. Myers et al. (1997) attributed the collapse of cod fisheries in Atlantic Canada to the retrospective problem. The speculated that the RE pattern observed in the cod fishery resulted from biased catch data because of the exclusion of discarded catch data in the assessment.

Gavaris (1993) claimed that the bias arising from model specification is likely to be an important contributory factor in the VPA tuned according to equation (1).

Previous studies showed that the simultaneous method tended to yield positive retrospective errors in estimating current stock sizes (Parma 1993; Mohn 1999; Rajakaruna et al. 2005). The simulation study suggests that the simultaneous method estimated stock biomass tends to have much larger estimation errors and positive biases for the two most recent years compared with those for earlier years. This suggests that the simultaneous method may have the retrospective problem, consistent with the results derived from previous studies (Sinclair et al. 1990; Mohn 1999; Rajakaruna et al. 2005). The stepwise procedure, however, yields stock biomass estimates for the two most recent years having similar and small estimation errors and biases compared with those of previous years, implying the stepwise procedure having no obvious retrospective problem. Thus, when an age-specific curvilinear relationship exists between survey abundance index and stock abundance, the common VPA can result in retrospective problems in estimating current stock biomass. The stepwise procedure can, however, yield improved estimates with no obvious retrospective problem.

Many studies have suggested that the fishery-dependent abundance index may not be proportional to stock abundance because of partial recruitment, spatial and temporal aggregation of fish distribution, fish behavior associated with various life history processes, and fleet dynamics (e.g., Paloheimo and Dickie 1964; Crecco and Savoks 1985; Hilborn and Walters 1992; Harley et al. 2001; Salthang and Anes 2003). However, for the fishery-independent abundance index, because of effective temporal and spatial coverage of surveys and often small sample sizes, the relationship between the abundance index and stock abundance may also be curvilinear (Swain and Sinclair 1994; Hilborn and Peterman 1996; NRC 1998). The movement of many fish species tends to be size dependent, resulting in possible size-dependent temporal and spatial aggregations. Thus, the curvilinear relationships between abundance index and stock abundance are also likely to be size/age dependent. The simulation study shows clearly that such a relationship can result in retrospective problems when the common VPA method is used for estimating current stock biomass, but cause no retrospective problem when the stepwise approach is used.

The stepwise approach estimates the size of each cohort in the current year age by age. The estimation for each cohort is not fully independent of each other because estimation for a young age group needs to use the estimates derived for elder age groups. The estimation for an old age group is, however, less affected by the estimation for a young age group because most data points in the regression analyses (i.e. Eqs. (5) and (6)) are calculated from complete cohorts. The estimation for an old age group mainly relies on the information on the sizes of complete cohorts, which are considered to be well estimated (Hilborn and Walters 1992), and thus is more reliable. For a more recent year class, the estimation of its current size mainly depends on the information on incomplete cohorts, and is thus considered less reliable. This might explain why the percentage of variances that can be explained by equation (4) decreased with decreasing ages (Table 1).

The common VPA estimates all parameters simultaneously, resulting in high correlations between estimated parameters of different age groups. Thus, a small change in parameters for one age group may lead to changes in estimations of parameters for other age groups. The simultaneous estimation of all parameters across all ages and years reduces the flexibility of the model in addressing the differences between ages and between years, which are likely to exist due to size-dependent fish distributions and variations among years. For the stepwise approach, the correlations of parameters among different age groups were likely weaker, in particular for old age groups for which most data points in the regression analysis (i.e. Eq. (4)) were from size estimates of the complete cohorts which are considered to be more reliable.

Unlike the common VPA approach, we did not make an assumption on the linear dependence of the abundant index on the abundance in our equation (4), in the stepwise method. The results, however, showed that the estimator of slope $b_{1}$ from the regression analysis of the cod data was not significantly different from 1 . This implies that the hypothesis of having a linear relationship between the abundance index and the abundance cannot be rejected. Thus, for the field data we used in this study, the abundance index is statistically proportional to stock biomass and the common VPA uses the correct functional relationship between the abundance index and stock abundance. Even under this scenario, the stepwise tends to perform better while the performance of the simultaneous method tends to be consistent with its performance in the simulation study with large retrospective errors.

The anti-log used in equation (5) may introduce a small negative bias in estimating mean values of cohort sizes in the current year. A correction factor can be derived to reduce such a bias for estimating mean for a lognormal distribution (Parzen 1960; Hilborn 1985; Quinn and Deriso 1999). The negative biases may contribute to the differences between estimates derived from the stepwise approach and common VPA. However, because the magnitude of the difference in estimated cohort sizes using these two methods differs greatly among age groups, the anti-log used in equation (5) is unlikely to be the main cause for large differences between the two approaches.

The objective function of the simultaneous method was described in equation (1). The equation does not, however, consider the potential curvilinear relationship between abundance index and stock abundance. To consider this relationship, equation (1) for the simultaneous method can be modified as minimizing $\sum_{y=1}^{Y} \sum_{a=1}^{A}\left[\ln \left(I_{a, y}\right)-\ln \left(q_{a} N_{a, y}^{\gamma_{a}}\right)\right]^{2}$, where $\gamma_{a}$ is a density-dependent factor describing possible curvilinear relationship between the abundance index and stock abundance. In a limited analysis we did which considered this relationship, 
the simultaneous estimation of all the parameters across all the ages and years made the poor estimation of $\gamma_{a}$. A simulation suggests that the relationship between $q$ and $\gamma_{a}$ is almost linear for a given age class, suggesting that the estimation of these two parameters are highly correlated. This implies that $\gamma_{a}$ and $q$ cannot be well estimated.

The stepwise fashion in estimating stock sizes for incomplete cohorts implies that errors occur in the old age groups may propagate in a series individual regression predictions for cohort sizes in younger ages. However, the propagation errors can be quantified. Because the stepwise procedure utilizes a standard statistical method, the error of the estimate generated by equation (5) can be readily quantified (e.g., using boostrap method). The sizes of incomplete cohorts at any age could be written as a recursive relationship between the cohort sizes at younger ages and their respective indices. For example, by substituting equation (5) into equation (3), the numbers at age $a-1$ in year $y-1$ would be written as

$$
N_{a-1, y-1}=\exp \left[\frac{\ln \left(I_{a, y}\right)-b_{0, a}}{b_{1, a}}\right] e^{M}+C_{a-1, y-1} e^{\frac{M}{2}} .
$$

Then, it is just a matter of continuing this process for all ages. Thus the propagation of errors can be quantified as a function of the sequential population process. For the simultaneous method, it is, however, much more difficult to address the issues of error propagation because of complex estimation process.

For many fisheries, multiple abundance indices are often available. If the stepwise procedure is used, there will be multiple sets of parameters $b_{a, 0}$ and $b_{a, 1}$ estimates and the back calculated cohort sizes in equation (5) will not be the same for a given age group. In this case, we have to either combine the abundance indices into one or apply the stepwise procedure to each set of abundance index and then develop a decision rule or a joint estimation technique for selection of the best estimates. More work needs to be done to address this potential problem.

Xiao and Wang (2007) found that using equation (3) as a dynamic model might be problematic. The integral of $F_{t}$ over the time interval of sampling is well defined whereas $F_{t}$ itself at the point of actual sampling approaches to infinity as the interval of sampling goes to zero. Equation (3) corresponds to the case where catch is taken from the fish population instantaneously in the middle of the year, which makes the interpretation of $F_{t}$ difficult (Xiao 2007). Thus, this work represents an approximation. This issue needs to be addressed in future research.

This study found no apparent retrospective problem for the stepwise estimator in the presence of curvilinear relationship between abundance index and stock abundance. This may suggest that the stepwise approach is more desirable than the common VPA for analyzing catch-at-age data. For many fisheries, because of high costs of obtaining a fishery-independent abundance index, CPUE or other fishery-dependent abundance index data have to be used in tuning VPA. The indices derived from fishery-dependent data are more likely to have curvilinear relationship in indexing stock abundance (Salthang and Anes 2003), making the stepwise procedure more desirable. The common VPA method can, however, provide background comparisons for the estimated stock biomass. We suggest that both the stepwise approach and common VPA method be used and the difference be identified and evaluated. Such a comparative approach may help us better understand the retrospective problem associated with a virtual population analysis of agestructured data, thus improving fisheries stock assessment and management.

Acknowledgements. The financial support of this study was partially provided by the Key Laboratory of Shanghai Education Commission for Oceanic Fisheries Resources Exploitation, Shanghai Fisheries University, and National Taiwan University. We thank the constructive and helpful comments from two anonymous reviewers.

\section{References}

Chatfield C., 2003, The analysis of time series, an introduction. $6^{\text {th }}$ edn. London, Chapman \& Hall/ CRC Press.

Crecco V.A., Savoks T.F., 1985, Density-dependent catchability and its potential causes and consequences on Connecticut River American shad, Alosa sapidissima. Can. J. Fish. Aquat. Sci. 42, 1649-1657.

Darby C.D., Flatman S., 1994, Virtual population analysis: version 3.1 (Windows/DOS) user guide. MAFF Inform. Technol., 85 p.

De Valpine P., 2002, Review of methods for fitting time-series models with process and observation errors and likelihood calculations for nonlinear, non-Gaussian state-space models. Bull. Mar. Sci. 70, 455-471.

Gascon D., 1988, Catch projections. In: Rivard D. (Ed.), Collected papers on stock assessment methods. CAFSAC Res. Doc 88/61.

Gavaris, S., 1988, An adaptive frame work for the estimation of population size. CAFSAC Res. Doc. 88/29

Gavaris S., 1993, Analytical estimates of reliability for the projected yield from commercial fisheries. In: Smith S.J., Hunt J.J., Rivard D. (Eds.) Risk evaluation and biological reference points for fisheries management. Can. Spec. Publ. Fish. Aquat. Sci. 120, 185192.

Harley S.J., Myers R.A., Dunn A., 2001, Is catch-per-unit-effort proportional to abundance? Can. J. Fish. Aquat. Sci. 58, 1760-1772.

Hilborn R., 1985, Simplified calculation of optimum spawning stock size from Ricker's stock recruitment curve. Can. J. Fish. Aquat. Sci. 42, 1833-1834.

Hilborn R., Walters C., 1992, Quantitative fisheries stock assessment: choice, dynamics and uncertainty. New York, Chapman and Hall.

Hilborn R., Peterman R.M., 1996, The development of scientific advice with incomplete information in the context of the precautionary approach. FAO Fish. Techn. Pap. 350, 2, pp. 77-101.

ICES, 1991, Report of the working group on methods of fish stock assessment. St.John's NF, ICES CM 1991/Assessment 25.

Megrey B.A., 1989, Review and comparison of age-structured stock assessment models from theoretical and applied points of view. Am. Fish. Soc. Symp. 6, 8-48.

Mohn R.K., 1993, Bootstrap estimates of ADAPT parameters, their projection in risk analysis and their retrospective patterns. In: Smith S.J., Hunt J.J., Rivard D. (Eds.) Risk evaluation and biological reference points for fisheries management. Can. Spec. Publ. Fish. Aquat. Sci. 120, 173-184. 
Mohn R., 1999, The retrospective problem in sequential population analysis: An investigation using cod fishery and simulated data. ICES J. Mar. Sci. 56, 473-488.

Myers R.A., Hutchings J.A., Barrowman N.J., 1997, Why do fish stocks collapse? The example of cod in Atlantic Canada. Ecol. Appl. 7, 91-106.

National Research Council (NRC), 1998, Improving Fish Stock Assessment. The National Academy Press, Washington, DC.

Paloheimo J.E., 1980, Estimating mortality rates in fish populations. Trans. Am. Fish. Soc. 109, 378-386.

Paloheimo J.E., Dickie L.M., 1964, Abundance and fishing success. Rapp. P.-V. Réun. Cons. Int. Explor. Mer 155, 152-163.

Parma A.N., 1993, Retrospective catch-at-age analysis of pacific halibut: implications on assessment of harvesting policies. In: Kruse G., Eggers D.M., Pautzke C., Marasco R.J., Quinn II T.J. (Eds.). Proc. Int. Symp. Management Strategies for Exploited Fish Populations. Alaska Sea Grant College Program, pp. 287265.

Parzen E., 1960, Modern probability theory and its application. John Wiley and Sons, New York.

Patterson K.R., Kirkwood G.P., 1995, Comparative performance of ADAPT and Laurec-Shepherd methods for estimating fish population parameters and in stock management. ICES J. Mar. Sci. 52, 183-196.

Pope J.G., 1972, An investigation of the accuracy of Virtual Population Analysis using cohort analysis. Res. Bull. ICNAF 9, 65-74.

Quinn T.J., Deriso R.B., 1999, Quantitative fish dynamics. Oxford University Press, Inc. New York.

Rajakauna H., Chen Y., Snelgrove P., 2005, Is retrospective error a "true error"? Mathematical basis of adaptive framework for virtual population analysis. Math. Phys. Fish. Sci. 3, 36-64.
Rivard D., Foy M.G., 1987, An analysis of errors in catch projections for Canadian Atlantic fish stocks. Can. J. Fish. Aquat. Sci. 44, 967-981.

Salthang A., Anes S., 2003, Catchability and the spatial distribution of fishing vessels. Can. J. Fish. Aquat. Sci. 60, 259-268.

Secor D.H., 2007, The year-class phenomenon and the storage effect in marine fishes. J. Sea Res. 57, 91-103.

Shelton P.A., Stansbury D.E., Murphy G.R., Lilly G.R., Brattey J., 1996, An assessment of the cod stock in NAFO divisions 2J+3KL. NAFO SCR Doc. 90/96.

Shepherd J.G., 1999, Extended survivors analysis: an improved method for the analysis of catch-at-age data and abundance indices. ICES J. Mar. Sci. 56, 584-591.

Sinclair A., Gascon D., O’Boyle R., Rivard D., Gavaris S., 1990, Consistency of some northwest Atlantic ground fish stock assessments. NAFO SCR Doc. 90/96.

Smith S.J., Gavaris S., 1993, Evaluation the accuracy of projected catch estimates from sequential population analysis and trawl survey abundance estimates. In: Smith S.J., Hunt J.J., Rivard D. (Eds.) Risk evaluation and biological reference points for fisheries management, Can. Spec. Publ. Fish. Aquat. Sci. 120, 163172.

Swain D.P., Sinclair A.F., 1994, Fish distribution and catchability: what is the appropriate measure of distribution? Can. J. Fish. Aquat. Sci. 51, 1046-1054.

Walters C., Maguire J., 1996, Lessons for stock assessment from the northern cod collapse. Rev. Fish Biol. Fish. 6, 125-137.

Xiao Y. 2007, The fundamental equations of multi-species virtual population analysis and its variants. Ecol. Model. 201, 477-494.

Xiao Y., Wang Y.G., 2007, A revisit to Pope's cohort analysis. Fish. Res. 86, 153-158. 